Navicula incerta was by no means a common diatom in the gathering; in the six strewn slides examined only seven specimens were observed. These varied somewhat in length from $0.014 \mathrm{~mm}$. to $0.019 \mathrm{~mm}$, but they were all $0.006 \mathrm{~mm}$. in breadth. In each of the forms examined the number of striæ was uniform at 16 in $0.010 \mathrm{~mm}$., and the lineolations $15-17$ in $0.010 \mathrm{~mm}$.

P. T. Cleve ${ }^{7}$ describes this diatom as follows: "Navicula incerta (Grun 1880) linear with slightly convex margins and obtuse ends. Length $.016 \mathrm{~mm}$., breadth $.006 \mathrm{~mm}$., striæ $15 \mathrm{in} 010 \mathrm{~mm}$. not radiate; axial and central areas indistinct. Note. A small form with coarse striæ unknown to the authorMarine".

We are appreciative of the kindness of the Director of the Royal Botanic Gardens, Kew, for supplying a number of the references quoted.

$$
\text { Frederiak Burke. }
$$

12 Queen's Road, Chester.

\section{Briardale Road,} Heaton, Bradford.

"Burke, F., NATURE, 150, 6 io (1942).

2 Sherlock, Mem. Geol. Survey, "Mineral Resources of Great Britain, Rocksalt and Brine", 18, 54 (1921).

${ }^{3}$ Kew. No Herbarium record.

"Biological Abstracts back to 1927.

5 Tilden's "Index Algarum Universalis".

${ }^{6}$ Index to the articles on, and the references to, Diatomacer in the Transactions and Journal of the Roy. Micro. Soc., Lond. (18531915).

"Cleve, P. T., "Synopsis of the Naviculoid Diatoms", Part 2, p. 26.

\section{Fluorescence of Anthracene in Presence of Naphthacene}

IT is known that pure naphthacene crystal (I) fluoresces very feebly, but in dilute solid solution of anthracene (II), the crystal fluoresces with its charact. eristic yellow-green light; and the blue fluorescence of anthracene is quenched.<smiles>C1[IH][IH]CC2CC3CC4C[IH][IH]CC4CC3CC12</smiles>

(I)

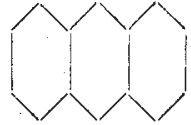

(II)

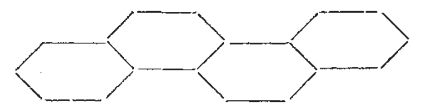

(III)

This phenomenon is represented as follows: in dilute solid solution the anthracene molecules easily absorb light energy and release an 'exciton' which causes naphthacene to fluoresce. We find that solid naphthacene fluoresces not only in anthracene, but also in chrysene (III); there is a little shifting of the fluorescence bands, depending on the substance with which it is mixed.

In view of this fact, the study of fluorescence spectra in alcoholic solution of anthracene, naphthacene and the mixture of the above two is interesting. In alcoholic solution, anthracene has four fluorescence bands (excited by $3,650,4,046$ of the mercury arc), and naphthacene has three fluorescence bands on the red side of the fluorescence bands of anthracene; the mixture has both the fluorescence of anthracene and of naphthacene. Three solutions were prepared, one of pure anthracene, the other of pure naphthacene, and the third a mixture of the two. The number of gram molecules per c.c. of anthracene and of naphtha. cene in the mixture were identical with those of the pure substances taken separately. Exposures were given for the same time and under identical conditions.

It was found that there is no appreciable change of intensity of the fluorescence bands of anthracene due to the presence of naphthacene; or of that of the fluorescence bands of naphthacene due to the presence of anthracene. Absorption spectra of the above three solutions confirm the result:

\section{Indian Association for the Cultivation of Science, \\ 210 Bowbazar Street Calcutta. March 26.} S. C. Ganguhy.

\section{Post-War Agricultural Education}

IN the last paragraph of the second column on p. 540 of the article on post-war agricultural education published in NATURE of May 15, quotations from the Report of the Luxmoore Committee dealing with courses in agriculture and horticulture are summarized as follows: "It is difficult to understand that what is right for horticultural graduates is wrong for agriculture". It is not clear from the text of the article on what grounds this charge of inconsistency is made. Two constructions are possible, both of which rest on a misunderstanding of the Committee's intentions.

If the objection is to the establishment in universities of graduáte courses leading to diplomas in horticulture, it is without foundation because there is a similar recommendation in the case of agriculture. Further, the proposed diploma courses in both subjects would be of an advanced nature for those already possessing a degree, and would be given in a university.

On the other hand, it may be that the objection refers to the statement that instruction in horticulture should be given in a "separate department". The fact that some agricultural colleges are now departments of a university may have given rise to the assumption of a difference in treatment of the two subjects. The idea of a separate department for horticulture reflects the Committee's view that horticultural education requires separate and different treatment and should not be considered as subservient to agriculture. The departments proposed were intended to be an integral part of the university concerned, and not physically isolated as in the case of the agricultural colleges. It was envisaged by the Committee that the teaching of agriculture and horticulture in a university should be on the same lines, namely, in separately constituted university departments. Thus the statement quoted that for agriculture "the whole of any course leading to a degree should be taken in the University itself so that the benefit of contact with teachers and students engaged in other subjects should not be lost" applies with equal force to the teaching for degrees in horticulture.

Ronald EDE

(Secretary of the

School of Agriculture, Luxmoore Committee). 